SMART TECHNO PARENTING:

\title{
ALTERNATIF PENDIDIKAN ANAK PADA ERA TEKNOLOGI DIGITAL
}

\author{
Hasan Baharun1; Febri Deflia Finori² \\ 1,2 Universitas Nurul Jadid, Probolinggo, Indonesia \\ 1ha54nbaharun@gmail.com, 2deflifinori02@gmail.com
}

\begin{abstract}
Abstrak
Penelitian ini adalah kajian pustaka yang mengungkap tentang bagaimana cara mendidik dan mempersiapkan anak di era tekhnologi digital. Era digital merupakan tantangan tersendiri bagi orang tua dalam mendidik putra putrinya, sehingga harus pandai dalam memanfaatkan perkembangan tekhnologi untuk pendidikan putraputrinya. Hasil penelitian ini menegaskan bahwa salah satu alternatif pendekatan untuk mendidik anak di era tekhnologi digital ini adalah smart techno parenting. Pendekatan pendidikan ini menegaskan pentingnya untuk: 1) Mengkolaborasikan kemajuan teknologi dengan pendidikan anak, 2) Melek literasi informasi teknologi, 3) Membatasi waktu pemakaian produk tekhnologi digital, 4) Optimalisasi aktivitas positif, 5) Selektif memilih media untuk anak, 6) Monitoring lingkungan, baik di dunia maya maupun di sekitarnya.
\end{abstract}

Kata Kunci: Smart Techno Parenting; Anak; Era Teknologi Digital.

\begin{abstract}
Abstrak
This research is a literature review that reveals how to educate and prepare children in the era of digital technology. The digital age is a challenge for parents in educating their sons and daughters, so they must be clever in utilizing technological developments for the education of their children. The results of this study confirm that one alternative approach to educating children in the era of digital technology is smart techno parenting. This educational approach emphasizes the importance of: 1) Collaborating on technological progress with children's education, 2) Literacy literacy of information technology, 3) Limiting the time to use digital technology products, 4) Optimizing positive activities, 5) Selectively in choosing media for children, 6) Environmental monitoring, and both in cyberspace and around them.
\end{abstract}

Keywords: Smart Techno Parenting; Children; Digital Technology Era. 
Baharun, H., \& Finori, F. (2019). SMART TECHNO PARENTING: ALTERNATIF PENDIDIKAN ANAK PADA ERA TEKNOLOGI DIGITAL. Jurnal Tatsqif, 17(1), 52-69. https://doi.org/10.20414/ita.v17i1.625

\section{PENDAHULUAN}

Tanda dimulainya era Industri 4.0 dapat dilihat dari penomena digitalisasi informasi dan pemanfaatan kecerdasan buatan (artificial intelligence) secara massif di berbagai sektor kehidupan manusia untuk menjalankan tugas dan fungsi tertentu (Putrawangsa \& Hasanah, 2018). Digitalisasi informasi ini adalah tonggak yang membawa peradaban manusian ke zaman yang dikenal dengan istilah era digital. Pada era ini, segala informasi dapat diakses dengan mudah sesuai dengan keinginan dan kehendak para pengguna. Kemudahan ini tentunya memberikan dampak terhadap kehidupan manusia, khususnya kehidupan anak masa kini. Anak-anak yang hidup dan dipengaruhi oleh perkembangan teknologi ini kemudian dikenal dengan istilah generasi digital atau digital native.

Melihat perkembangan teknologi semakin pesat, pengawasan terhadap anak sangat penting untuk diaplikasikan mengingat terdapat banyak informasi yang telah diterima anak. Sementara seorang anak harus mampu memilah dan memilih informasi yang sesuai dengan tahapan-tahapan perkembangannya (Faisal, 2016). Dengan hadirnya teknologi yang semakin canggih memudahkan setiap kalangan untuk mudah mengakses informasi. Dalam hal ini teknologi memiliki peran yang sangat penting dalam pendidikan. Anak dapat mengakses jurnal, makalah dan artikel lainnya untuk bahan pembelajaran. Namun tidak dapat dipungkiri bahwa teknologi tidak lepas dari dampak negatif bagi beberapa kalangan.

Orang tua menginginkan anak menjadi generasi yang berkualitas di masa depan dengan mampu menghadapi tantangan zaman saat ini. Namun, fakta yang terjadi dengan adanya perkembangan teknologi membuat anak lebih banyak menghabiskan waktu bermain games online, kurang peduli terhadap lingkungan sekitar, kurangnya interaksi dengan orang tua, bahkan malas untuk belajar. Hal ini terjadi karena kurangnya kemampuan anak untuk memahami dampak positif dan negatif digital yang digunakan dan kurangnya pengawasan dari orang tua (Putri, 2018). Fakta lain yang terjadi adalah 
Baharun, H., \& Finori, F. (2019). SMART TECHNO PARENTING: ALTERNATIF PENDIDIKAN ANAK PADA ERA TEKNOLOGI DIGITAL. Jurnal Tatsqif, 17(1), 52-69. https://doi.org/10.20414/ita.v17i1.625

teknologi internet berdampak kepada perilaku dan kehidupan generasi masa kini. Anak masa kini telah mengenali dengan akrab mengenai internet yang teraplikasikan melalui berbagai perangkat seperti: komputer, tablet, smartphone, laptop, handphone, dan perangkat lainnya. Banyak dari anak masa kini menggunakan perkembangan teknologi hanya untuk hiburan dan mencari berita tidak untuk sarana pembelajaran (Chalim \& Anwas, 2018).

Pada hakikatnya orang tua adalah aktor yang sangat berperan dalam proses pendidikan anak. Pendampingan orang tua terhadap anak sangat dibutuhkan dalam setiap langkah perkembangannya. Orang tua memiliki tanggung jawab penuh dalam memenuhi kebutuhan anak, mendampingi, mengajari, membimbing, mendidik dan mengarahkan. Tanggung jawab dari orang tua tidak hanya dalam materi, namun juga meliputi sisi spiritual, fisik moral, sosial dan kejiwaan anak. Tanggung jawab inilah yang dimaksud dengan proses pembentukan pendidikan anak yang bertujuan menciptakan anak menjadi manusia yang sehat, cerdas, berakal, berkarakter mulia (Hefniy, 2017), berakhlak dan mampu menjadi generasi yang berkualitas untuk masa depan yang cerah (Muslima, 2015).

Pendidikan menjadi kebutuhan untuk menghadapi masa depan, karena tanpa adanya pendidikan manusia akan merasa sangat sulit untuk mengetahui dan mengembangkan potensi yang terpendam dalam dirinya. Pendidikan merupakan salah satu jembatan atau salah satu alternatif untuk mengembangkan potensi diri dan mampu untuk membawa manusia menuju kepribadian yang lebih berkualitas, bermutu, dan mampu menghadapi era globalisasi pada zaman ini (Rozana, Wahid, \& Muali, 2017).

Perwujudan manusia berkualitas tersebut menjadi tanggung jawab pendidikan, terlebih dalam mempersiapkan peserta didik yang nantinya akan lebih berperan menjadikan diri sebagai generasi bangsa, mengembangkan potensi diri yang tangguh, mandiri, kreatif dan profesional pada kemampuannya masing-masing. Hal tersebut sangat dipandang perlu, terlebih dalam menghadapi masa milenial (Mumtahanah, 2015). 
Baharun, H., \& Finori, F. (2019). SMART TECHNO PARENTING: ALTERNATIF PENDIDIKAN ANAK PADA ERA TEKNOLOGI DIGITAL. Jurnal Tatsqif, 17(1), 52-69. https://doi.org/10.20414/ita.v17i1.625

Pendidikan pertama bagi anak adalah orang tua sebagai madrosatul ula, namun yang terjadi adalah sebagian orang tua menuntut guru maupun pihak lembaga pendidikan untuk menjadikan buah hatinya sebagai manusia yang mempunyai kemampuan unggul dari setiap aspek perkembangannya (Henny Puji Astuti, 2013). Memang dalam masa perkembangan anak memerlukan dukungan dari lembaga pendidikan. Namun, titik sepenuhnya ada pada orang tua, karena lembaga pendidikan merupakan unsur penunjang dalam perkembangan anak (Baharun \& Maryam, 2019).

Saat ini era digital memiliki pengaruh yang sangat signifikan dalam berbagai bidang di masyarakat, meliputi pendidikan, perekonomian bahkan dalam perilaku dan dampak lainnya (Maulidiyah, 2018). Maka dari itu, dalam membimbing dan mendidik anak untuk menjadi generasi yang baik maka diperlukan pola pendekatan yang dilakukan orang tua untuk memudahkan proses pembentukan generasi yang baik.

Berbicara tentang pendampingan anak dan pengasuhan anak, Smart Parenting menjadi alternatif sebagai pola asuh ideal bagi orang tua atau pendidik (Rozana et al., 2017). Smart Parenting adalah pola pendidikan di mana seorang pendidik, mendampingi dan membimbing perkembangan dan tahap pertumbuhan peserta didik, mengarahkan kesenjangan yang ada pada diri peserta didik dan memberinya solusi terhadap kehidupan yang baru dialami oleh anak. Smart Parenting mampu mewujudkan keinginan bangsa dan mampu memudahkan orang tua dalam membina anak untuk menjadi generasi emas (golden age) di masa depan (Ilmy, Wahid, \& Muali, 2018).

Fokus utama kajian ini adalah bagaimana strategi orang tua dalam mempersiapkan anaknya guna menghadapi era tekhnologi digital, agar anak dapat tumbuh dan berkembang sesuai dengan apa yang diinginkan oleh orang tua melalui smarttechno parenting. Implementasi konsep smarttechno parenting ditujukan untuk mendidik dan mempersiapkan anak menjadi generasi emas (golden age) di tengah perkembangan informasi dan tekhnologi. 
Baharun, H., \& Finori, F. (2019). SMART TECHNO PARENTING: ALTERNATIF PENDIDIKAN ANAK PADA ERA TEKNOLOGI DIGITAL. Jurnal Tatsqif, 17(1), 52-69. https://doi.org/10.20414/ita.v17i1.625

Smart techno parenting sebagai bagian dari konsep parenting merupakan konsep yang baru dan unik dalam mendidik anak di era tekhnologi ini, khususnya dengan banyaknya anak yang kecanduan terhadap produkproduk tekhnologi, seperti gadget, laptop dan media tekhnologi lainnya. Banyak penelitian tentang parenting, akan tetapi, kajian ini lebih spesifik pada upaya mendidik dan mendampingi anak secara cerdas di era digital dengan mengkolaborasikan kemajuan tekhnologi untuk menjadi sarana pendidikan yang positif bagi anak.

\section{KERANGKA TEORI}

\section{Smart Techno Parenting}

Setiap keluarga merupakan suatu sistem, suatu kesatuan yang dibentuk oleh bagian bagian yang saling berhubungan dan berinteraksi. Hubungan yang tidak pernah hanya berlangsung satu arah, namun ada proses timbal balik antar keduanya. Secara langsung maupun tidak langsung, sikap dan pengasuhan orang tua akan mempengaruhi terhadap kemampuan pengendalian emosi anak. Pola asuh yang baik dalam keluarga dapat membuat seorang anak mempunyai kemampuan intelektual dan fisik yang bagus, termasuk perkembangan emosi dan sosialnya. Pola asuh yang baik itu ditunjukkan dengan orangtua yang sangat mencintai, penuh perhatian, dan sangat responsif terhadap anakanaknya (Andriyani, 2018).

Berbicara tentang strategi orang tua dalam mendidik anak maka perlu membahas tentang pola asuh orang tua dalam mendidik anak. Pada masa kini sudah sangat lumrah dikenal istilah parenting yang memiliki rasa lebih aktif dari parenthoot. Istilah parenting atau parenthoot adalah kata kerja yang berarti tahapan menjadi orang tua, melakukan sesuatu terhadap anak untuk kebaikan anak dimasa yang akan datang (Rahmat, 2018). 
Istilah parenting dalam kamus bahasa Indonesia dikenal dengan pengasuhan yang kata dasarnya adalah "asuh" yang memiliki arti menjaga, merawat dan mendidik namun arti dari pengasuhan sendiri adalah proses, cara dan perbuatan pengasuh. Dengan demikian dapat disimpulkan bahwasannya parenting merupakan suatu pengasuhan orang tua terhadap anak.

Salah satu metode parenting yang sering diperbincangkan adalah pendekatan smart parenting. Smart Parenting merupakan metode pendidikan cerdas yang dierapkan oleh orang tua. Parenting sendiri adalah sebagai proses interaksi antara orang tua dengan anak-anak mereka mengenai perkembangan potensi yang dimiliki (Rabiatul Adawiah, 2017). Smart Parenting adalah keseluruhan yang dapat orang tua lakukan untuk seorang anak, dari hal yang terkecil hingga besar, hari demi hari yang dapat menciptakan suasana yang hangat dalam rumah tangga dan hubungan antara anak dengan orang tua.

Era digital adalah leburan dari era revolusi industri 4.0 di mana pada era ini sangat banyak menghadirkan perubahan. Era digital bukanlah hal yang harus dilawan namun era ini adalah konsekuensi yang harus diimbangi dan diterima oleh masyarakat. Banyak perubahan yang terjadi di kehidupan masyarakat dari berkembangnya teknologi di era digital ini, dari sisi perekonomian, sosial, dunia bisnis, bahkan dalam pendidikan sekalipun.

Orang tua memfasilitasi anak dengan SmartPhone, karena orang tua tidak ingin anaknya rewel. Kebanyakan orang tua memberikan fasilitas berupa tablet atau Smart Phone untuk menenangkan anak yang rewel di kala sibuk. Namun, membiarkan mereka bermain asyik dengan fasilitas yang dimiliki tanpa pengawasan dari orang tua juga akan membahayakan perkembangan mental anak. Terlebih ketika sang anak membuka konten yang seharusnya tidak dibuka. (Watie, 2014). 
Berangkat dari hal tersebut di atas, maka peneliti menawarkan konsep Smart techno parenting, di mana konsep ini menggabungkan antara konsep parenting dan konsep perkembangan tekhnologi. Smart techno parenting hadir sebagai varian baru dalam kerangka mendidik anak secara smart di era tekhnologi, dengan memanfaatkan kemajuan teknologi yang sejatinya memang sangat membantu dalam mendidik anak, agar anak memiliki ketahanan mental spiritual di tengah gencarnya tekhnologi informasi yang berkembang.

Smart techno parenting dimaknai sebagai strategi mendidik dan menumbuhkembangkan potensi anak secara cerdas dengan memposisikan orang tua untuk lebih aktif, kreatif dan "melek" terhadap perkembangan tekhnologi. Smart techno parenting merupakan serangkain kegiatan yang dilakukan oleh orang tua, mulai dari hal terkecil sampai pada hal terbesar dalam melakukan interaksi dengan anak secara komunikatif, intensif dan penuh keterbukaan dalam kerangka penggunaan dan pemanfaatan tekhnologi informasi yang ada dengan menjadikan kemajuan teknologi sebagai sarana pendidikan anak yang positif.

\section{Era Digital dan Dampak Bagi Kehidupan}

Revolusi digital dan era disrupsi teknologi merupakan istilah lain dari era Industri 4.0. Disebut revolusi digital karena adanya profilerasi komputer dan otomatisasi pencatatan dari semua bidang. Salah satu keunikan dari era Industri 4.0 adalah pengaplikasian kecerdasan buatan atau (artificial intelligence). Hampir dari semua bidang terjadi otomatisasi dengan hadirnya kemajuan teknologi. Kemajuan teknologi yang berhasil menciptakan perubahan terhadap cara beraktifitas manusia dalam skala, ruang lingkup, kompleksitas, dan transformasi dari pengalaman hidup sebelumnya (Yahya, 2018). Dunia pendidikan pun tidak terlepas dari pengaruh perkembangan teknologi digital (Harto, 2018). Era digital 
sendiri terlahir dari rahim serta pesatnya perkembangan era global atau globalisasi (Yahya, 2018).

Banyak media sosial yang tersebar di era digital yang memudahkan manusia mengakses sesuatu. Media sosial menjadi salah satu media yang memungkinkan para pengguna menciptakan dunia sendiri bagi mereka para pengguna. Di era digital menjadikan sosial media sebagai kebutuhan primer bagi masyarakat kebanyakan, sekalipun ada segelintir dari mereka yang tidak mengikuti perkembangan zaman. Hadirnya sosial media tidak memandang siapapun, kalangan anak-anak, kalangan dewasa pun tertuntut mengikuti majunya media sosial. Terdapat berbagai macam sosial media yang dijadikan tempat berlabuh dari segala keluh kesah masyarakat (Maulidiyah, 2018).

Hadirnya teknologi informasi telah membuka mata dunia akan sebuah dunia yang baru, interaksi dengan cara yang baru, market place baru, dan sebuah jaringan bisnis dunia yang tanpa batas. Sangat disadari betul dengan hadirnya perkembangan teknologi yang disebut internet, telah mengubah pola interaksi masyarakat, interaksi bisnis, ekonomi, sosial, dan budaya. Internet telah memberikan kontribusi yang sangat besar terhadap masyarakat, perusahaan industri maupun pemerintah bahkan didalam pendidikan sekalipun. Kemajuan teknologi digital di era digital ini mendorong penyebaran informasi yang semakin cepat dengan mudahnya penyebaran informasi dari belahan dunia membuat perubahan kehidupan dari segala aspek (Mubara, 2017).

Secara teoritis dengan adanya kemajuan teknologi digital memudahkan segala sesuatu dengan memanfaatkan internet yang ada, bahkan dalam dunia pendidikan sekalipun. Namun, sayangnya tidak ada penyaringan di dalam internet tersebut. Segala informasi baik atau tidak baiknya dapat dilihat bahkan diakses di dalamnya karena kurang aktifnya pihak dalam menyebar dan menghapus konten negatif. 
Kemajuan teknologi memberikan pengaruh signifikan terhadap kehidupan masyarakat termasuk dalam ruang lingkup keluarga. Tidak bisa dipungkiri bahwa kemajuan teknologi saat ini terutama berbasis teknologi digital memberikan dampak positif dan juga dampak negatif bagi tumbuh kembang anak dalam keluarga. Teknologi digital, salah satunya berbasis internet menjadi satu aspek penting dalam faktor yang mempengaruhi perkembangan anak. Teknologi digital secara keseluruhan memberikan perubahan terhadap cara kita melakukan bisnis, melakukan penelitian, memilih hiburan, dan bahkan bagaimana bersosialisasi. Dengan hadirnya teknologi digital sesungguhnya bersifat netral, karena dampak positif dan negatif yang dapat muncul dari alat ini tergantung bagaimana pemanfaatannya. Teknologi digital memberikan pengaruh positif bila digunakan dengan bijaksana dan dapat menjadi alternatif dalam perkembangan anak.

Dengan adanya hal yang demikian orang tua sangat berperan didalamnya dalam mendidik anak-anaknya agar mengerti bagaimana dampak yang akan terjadi ketika mengenal dunia digitalisasi dengan membimbing dan mengarahkan anak-anaknya sebagai generasi bangsa di era selanjutnya.

\section{METODE PENELITIAN}

Penelitian ini mengunakan pendekatan kualitatif jenis library research, di mana peneliti memanfaatkan sumber kepustakaan untuk memperoleh data penelitiannya.

Tekhnik pengumpulan datanya dilakukan melalui pengumpulan data literar, yang teridiri dari bahan atau kajian pustaka yang koheren dengan objek pembahasan yang dimaksud.

Analisis datanya menggunakan content analysis (analisis isi), yaitu penelitian yang bersifat pembahasan mendalam terhadap isi suatu informasi tertulis atau tercetak dalam berbagai sumber informasi. 
Baharun, H., \& Finori, F. (2019). SMART TECHNO PARENTING: ALTERNATIF PENDIDIKAN ANAK PADA ERA TEKNOLOGI DIGITAL. Jurnal Tatsqif, 17(1), 52-69. https://doi.org/10.20414/ita.v17i1.625

\section{HASIL DAN PEMBAHASAN}

Peran orang tua dalam mempersiapkan anak di era tekhnologi digital memerlukan kerja yang ekstra dalam memahami karakter generasi digital dan mempersiapkan diri untuk menjadi orang tua yang berperan aktif dan cerdas dalam mengawal seorang anak tumbuh di era teknologi digital karena apabila orang tua tidak mampu cerdas mendidik anak di era digital amakaniscaya anak akan terjerumus terhadap hal yang tidak baik bagi masa perkembangannya.

Sebagian orang tua menyikapi hadirnya generasi digital dengan antusias. Mereka melihat penuh terhadap sisi positif dan produktivitas yang bisa dicapai di era digital. Sebagian orang tua juga menyikapinya dengan panik, khawatir, dan nyaris paranoid akan hadirnya kemajuan tekologi. Hal ini orang tua hanya melihat dampak negatif dari kemajuan teknologi (Chalim \& Anwas, 2018).

Berbicara tentang strategi orang tua dalam mendidik anak maka perlu membahas tentang pola asuh orang tua dalam mendidik anak (Stephanus Turibius Rahmat, 2018). Pola asuh inilah yang termasuk dalam smart parenting, karena orang tua tidak hanya memberikan aturan kepada anak, namun orang tua juga memberikan peluang untuk anak bereksplorasi mengungkapkan keinginannya. Smart Parenting merupakan metode pendidikan cerdas yang dierapkan oleh orang tua. Parenting sendiri adalah sebagai proses interaksi antara orang tua dengan anak-anak mereka mengenai perkembangan potensi yang dimiliki (Adawiah, 2017).

Kehadiran teknologi menjadikan orang tua lebih mudah menjadi orang tua yang smart, karena segala informasi sudah bisa didapat di dalam internet, yang sedari dulu hanya dapat didapat di tengah-tengah forum seminar atau yang lain sebagainya namun kini sudah bisa diakses dengan digital yang tersambung dengan internet dan dapat didapat dari berbagai sosial media. Facebook, instagram, e-mail, dan lain sebagainya, namun orang tua harus cerdas akan teknologi. Smart parenting di era digital adalah cara cerdas orang tua dalam mendidik anak dengan memanfaatkan kemajuan teknologi yang 
Baharun, H., \& Finori, F. (2019). SMART TECHNO PARENTING: ALTERNATIF PENDIDIKAN ANAK PADA ERA TEKNOLOGI DIGITAL. Jurnal Tatsqif, 17(1), 52-69. https://doi.org/10.20414/ita.v17i1.625

sejatinya memang sangat membantu dalam mendidik anak. Karena era disrupsi adalah era yang harus diimbangi dengan intelektual yang tinggi bagi orang tua.

Tidak bisa dipungkiri juga bahwasannya orang tua memfasilitasi anak dengan SmartPhone karena orang tua tidak ingin anaknya rewel. Kebanyakan orang tua memberikan fasilitas berupa tablet atau SmartPhone untuk menenangkan anak yang rewel di kala sibuk. Namun, membiarkan mereka bermain asyik dengan fasilitas yang dimiliki tanpa pengawasan dari orang tua juga akan membahayakan perkembangan mental anak. Terlebih ketika sang anak membuka konten yang seharusnya tidak dibuka. Tidak masalah bila orang tua mengatur settingan smartphone agar lebih bersahabat dengan anak. Dengan menggunakan aplikasi kidoz orang tua telah bisa mengganti konten di dalam smartphone menjadi konten khusus anak-anak. Cara lain yang dilakukan adalah memberikan fasilitas terhadap anak namun aplikasi yang diberikan di dalamnya adalah aplikasi-aplikasi edukasi adroid untuk anak (Watie, 2014).

Pada era digital seperti sekarang ini, orang tua harus menyesuaikan cara mendidik anak agar lebih bisa diterima anak. Pola asuh yang arif, positif, efektif, konstruktif dan transformatif atau dikenal techno smart parenting. Smart techno parenting adalah orang tua yang cerdas dalam mendidik anak di era teknologi dengan menjadikan kemajuan teknologi sebagai sarana pendidikan anak. Hal demikian akan sangat membantu pertumbuhan dan perkembangan anak ke arah yang lebih baik dan positif di era tekhnologi digital. Orang tua harus berusaha melindungi anak dari pengaruh buruk atau negatif penggunaan gadget dan teknologi informasi lainnya. Hal yang dapat dilakukan oleh orang tua dalam perspektif smart techno parenting sebagai langkah cerdas dalam mendidik anak di era digital sebagai berikut:

\section{Kolaborasi kemajuan teknologi dengan pendidikan anak}

Kemajuan teknologi digital semakin pesat bahkan diberbagai penjuru. Hadirnya kemajuan teknologi membuat pengaruh yang 
signifikan terhadap kehidupan manusia bahkan dalam pendidikan dan pengasuhan orang tua terhadap anak. Dengan kemajuan teknologi yang ada orang tua harus mampu memanfaatkannya menjadi sarana pendidikan bagi anak. Contoh media digital yang dapat digunakan sebagai sarana pendidikan bagi anak adalah paket al-Qur'an digital.

Paket Al-Qur'an digital dapat dijadikan sebagai sarana pendidikan bagi anak dan orang tua dapat mendidik anak dengan sendirinya. Perbedaan sangat terlihat ketika mengajarkan anak kepada orang lain dengan ketika memanfaatkan paket al-Qur'an untuk mengajarkan anak mengenai al-Qur'an sendiri. 1) Memudahkan orang tua mengetahui dengan sendiri bagaimana perkembangan anak dalam bacaan alQur'annya karena hakikatnya orang tualah pendidik sejati bagi anak; 2) Tingkat pencapaiannya lebih baik; 3) Lebih memudahkan orang tua untuk memantau pergaulan anak dalam pendidikannya, karena ketika anak berguru kepada orang lain membuatnya bergaul dengan siapapun dan tidak ada pantauan dari orang tua.

\section{Melek literasi informasi teknologi}

Dengan kemajuan teknologi di era digital sangat membantu orang tua dalam mendidik anak dan dapat mengajarkan anak tentang bagaimana era yang dihadapinya saat ini dalam artian anak tidak gagap akan digital. Dengan adanya kemajuan teknologi orang tua dapat meng-upgrade hal baru yang ada pada digital yang tersambung dengan internet untuk membekali anak dalam pendidikannya.

Di era digital saat ini proses belajar semakin dinamis dengan sarana elajar yang sagat beragam, seperti forum online (Muali, Islam, El, \& Bali, 2018), seminar, workshop, magang, dan lain sebagainya. Bahkan anak menemukan beragam pilihan sarana yang tidak dapat ditemukan di sekolah. Terdapat beberapa aplikasi tepat untuk dijadikan sarana pendidikan bagi anak di antaranya: 1) youtube kids, dalam aplikasi ini menampilkan berbagai video dengan tema anak-anak dari berbagai 
kalangan sumber yang terpercaya; 2) ABC kids, dalam aplikasi ini orang tua dapat mengajarkan mengenai abjad dengan mencocokkan huruf satu dengan yang lain. Dalam hal ini, orang tua menjadi coach (Pendamping) atau menjadi fasilitator yang dapat membantu anak untuk memunculkan potensi-potensi yang dimiliki (Mubara, 2017).

\section{Batasan waktu pemakaian digital}

Orang tua tidak melarang anak untuk mengenali dunia digital. Namun, orang tua juga perlu untuk membatasi anak dalam pemakaian digital. Disinilah, orang tua bertanggung jawab dalam mendidik anak dengan berusaha membatasi anak dalam penggunaan gadget dan media digital lainnya dengan cara menciptakan suasana yang lebih mengasyikkan (Herlina \& Setiawan, 2018).

Mengurangi durasi pemakaian digital dari yang semisal biasanya 8 jam maka diganti dengan 6 jam kemudian bertahap semakin menyusut dalam pemakaiannya. Hal yang demikian dapat berfungsi untuk merenggangkan saraf otak yang bekerja keras akan dunia maya yang dihadapi dan hal ini dapat terealisasi dengan pengalihan aktifitas yang lainnya. Pengurangan durasi pemakaian gadget juga berfungsi agar anak mengingat tentang pembelajaran di sekolah dan tetap semangat untuk mengerjakan tugas-tugas sekolah. Namun, tidak hanya memberikan aturan dalam pemakaian gadget melainkan orang tua juga memberikan contoh terhadap anak tentang bagaimana orang tua menggunakan gadget. Dengan contoh dan teladan ini akan menjadikan anak mudah untuk mematuhi peraturan tersebut dan paham bahwasannya peraturan yang diberikan tidak hanya untuk dirinya namun untuk keluarga, dan orang tuanya (Kurniawan, 2018).

\section{Optimalisasi aktifitas positif}

Orang tua harus selangkah lebih cerdas dari anak jika membolehkan anak menggunakan gadget, maka harus tetap diimbangi dengan aktivitasaktivitas lainnya yang menjadi prioritas, seperti bermain boneka, 
membaca, mengerjakan pekerjaan rumah, makan, mandi dan aktivitas yang melibatkan gerakan tubuh yang aktif. Banyak aktivitas yang bisa dilakukan dirumah maupun diluar rumah untuk mengurangi penggunaan digital bagi anak.

Hal yang demikian dilakukan agar anak tidak cenderung pasif dengan hal digital yang dinikmatinya dan diharapkan otak beristirahat sejenak dengan tidak berfikir keras akan digital yang diaplikasikannya. Menyediakan tempat sarana bagi anak untuk menyalurkan hobbi mereka agar sedikit lebih aktif mengeksplorasikan potensi yang dimiliki (Kayla Mubara, 2017). Dengan memberikan aktivitas lain yang mengasikan dapat meminimalisir anak dalam pemakian digital, dan mampu menjadikan hubungan orang tua dengan anak semakin hangat dalam keluarga.

\section{Selektif memilih media untuk anak}

Kemajuan teknologi digital tidak mampu utnuk dihindari. Hampir setiap generasi yang lahir di era digital sulit untuk dihindari dari kehadiran multimedia seperti teknologi yang semakin berkembang, televisi, musik, media sosial dan internet. Dalam hal ini orang tua perlu untuk memilih media atau tayangan yang sesuai dengan usia dan karakteristik anak. Orang tua juga perlu tegas dalam memberi aturan main bagi anak. Memilih konten atau media yang sesuai dengan fase anak dapat dilakukan dengan pemahaman orang tua mengenai teknologi, memilih sesuai dengan kategori yang telah tersedia, contohnya pada aplikasi play store memiliki kategori konten tersendiri misalnya, kategori keluarga yang berisi tentang konten anak-anak. Aplikasi lain juga tersedia youtube kids (youtube untuk anak-anak) yang ada parental control atau flter tayangan yang sesuai dengan umur anak (Dyna Herlina, Benni Setiawan, 2018).

\section{Monitoring lingkungan baik di dunia maya maupun di sekitarnya.}

Situs yang ada di dalam internet tidak semua pantas untuk diakses dan ditonton. Situs yang tidak sesuai dengan fase anak menjadi ancaman 
bagi pertumbuhan anak dan sangat mempengaruhi bagi moral anak. Cara yang dapat dilakukan adalah orang tua menjadi teman dari sang anak di sosial media untuk memantau bagaimana pergaulan anak di sosial media (Rahmat, 2018).

Dengan demikian, orang tua tetap harus mengontrol perilaku dan aktivitas anak di media sosial. Hal ini bertujuan untuk meminimalisir kecenderungan anak-anak jatuh dalam pergaulan yang tidak baik. Karena lingkungan keluarga, sekolah, dan masyarakat merupakan pengaruh terbesar dalam tumbuh kembang anak (Herlina, \& Setiawan, 2018). Maka dari itu sangatlah diperlukan orang tua memonitoring bagaimana lingkungan sekitar anak. Dengan cara meng-upgrade segala informasi dari kemajuan teknologi itu sendiri.

Banyak tantangan yang akan dihadapi oleh orang tua dalam mendidik dan membimbing anak pada era digital. Oleh karena itu, di era digital ini orang tua dituntut untuk menjadi orang tua yang cerdas mengimbangi kemajuan teknologi, hingga akhirnya kemajuan teknologi bisa mejadi sarana pendidikan bagi anak. Hadirnya era digital bukan untuk dihindari karena hal ini adalah konsekuensi yang harus dihadapi dengan cara meningkatkan intelektual untuk membekali anak dalam pendidikannya.

\section{KESIMPULAN}

Menjadikan anak sebagai generasi yang unggul pada era digital membutuhkan kerja ekstra dalam pendidikannya. Di era digital yang semakin maju akan teknologi, peran orang tua sangatlah mempengaruhi anak dalam masa perkembangannya. Keluarga merupakan tempat utama dan pertama bagi seorang anak dalam menjalani kehidupan hendaknya orang tua mengawasi dan membimbing dengan penuh kasih sayang, tegas, dan cermat.

Era digital hadir membawa dampak negatif dan hal positif. Pada era ini, orang tua diharuskan menjadi orang tua yang cerdas akan era digital semisal 
Baharun, H., \& Finori, F. (2019). SMART TECHNO PARENTING: ALTERNATIF PENDIDIKAN ANAK PADA ERA TEKNOLOGI DIGITAL. Jurnal Tatsqif, 17(1), 52-69. https://doi.org/10.20414/ita.v17i1.625

dalam teknologi. Demi menjadi smart parent dalam mendidik anak di era digital orang tua harus memahami tentang teknologi yang ada. Karena smart parenting teknologi adalah orang tua yang mampu mengimbangi era digital dengan memanfaatkannya sebagai sarana pendidikan bagi anak agar anak tidak gagap akan teknologi dan mampu belajar dengan kemajuan tekhnologi yang ada.

Smart parenting teknologi adalah orang tua yang cerdas dan mampu mengimbangi zaman dengan memanfaatkan kemajuan tekhnologi yang ada sebagai sarana pendidikan bagi anak. Dampak negatif akan dapat dihindari ketika orang tua mampu lebih aktif dan cerdas dalam tekhnologi, orang tua juga mampu memperoleh bahan-bahan smart parenting yang dulunya tidak bisa didapat kecuali dengan mengikuti pelatihan. Namun, saat ini kemajuan teknologi memudahkan orang tua mengakses materi smart yang menjadi bekal untuk diajarkan kepada anak-anaknya.

\section{DAFTAR PUSTAKA}

Andriyani, I. N. (2018). Pendidikan Anak Dalam Keluarga di Era Digital. FIKROTUNA: Jurnal Pendidikan Dan Manajemen Islam, 7(1), 790-803.

Baharun, H., \& Maryam, S. (2019). Building Character Education Using Three Matra of Hasan al-Banna's Perspective in Pesantren. Jurnal Pendidikan Islam 4, 4(2), 51-62. https://doi.org/10.15575/jpi.v4i2.2422

Chalim, S., \& Anwas, E. O. M. (2018). Peran Orangtua dan Guru dalam Membangun Internet sebagai Sumber Pembelajaran. Jurnal Penyuluhan, 14(1), 42-51.

Putri, D. P. (2018). Pendidikan Karakter Pada Anak Sekolah Dasar di Era Digital. AR-RIAYAH: Jurnal Pendidikan Dasar, 2(1), 38-50.

Herlina, D., \& Setiawan, B. G. J. A. (2018). DIGITAL PARENTING MENDIDIK ANAK DI ERA DIGITAL. (Novi Kurnia, Ed.) (1st ed.). Yokyakarta: Samudra Biru.

Maulidiyah, E. C. (2018). Penanaman nilai-nilai agama dalam pendidikan anak 
di era digital. Martabat: Jurnal Perempuan Dan Anak, 02(01), 72-90.

Watie, E. E. D. (2014). Implementasi smart Parenting untuk Meningkatkan Kualitas Pembelajaran di Lembaga PAUD.

Hefniy. (2017). Membangun Pendidikan Berbasis Islam Nusantara (Pendidikan Berbasis Karakter Atau Akhlakul Karimah ?). Jurnal ISlam, 1(1), 36-42.

Astuti, H. P. (2013). Smart Parenting: Upaya Peningkatan Kemampuan Kognitif Dan Kreativitas Anak Di Kelurahan Banjarjo, Boja, Kendal. Rekayasa, 11(2), 117-126.

Harto, K. (2018). TANTANGAN DOSEN PTKI DI ERA INDUSTRI 4.0. Jurnal Tatsqif, 16(1), 1-15. Retrieved from http://journal.uinmataram.ac.id/index.php/tatsqif/article/view/159

Kurniawan, H. (2018). Panduan Praktis Cara Terbaik Mendidik Anak Dalam Mengatasi Berbagai Persoalan. (Esti Utami, Ed.) (1st ed.). Sidoarjo: Media Cerdas.

Ilmy, A. N., Wahid, A. H., \& Muali, C. (2018). Urgensi Keterlibatan Wali Asuh Dalam Dinamika Pendidikan di Pesantren. Pendidikan Agama Islam (Journal of Islamic Education Studies), 6(1), 45.

Mubara, K. (2017). Smart Mom Funtuk Generasi Smart. (Dyas, Ed.). Yokyakarta: DIVA Press.

Muali, C., Islam, S., El, M., \& Bali, I. (2018). Free Online Learning Based On Rich Internet Applications ; The Experimentation Of Critical Thinking About Student Learning Style Free Online Learning Based On Rich Internet Applications; The Experimentation Of Critical Thinking About Student Learning Style.

Yahya, M. (2018). Era Industri 4.0: Tantangan dan Peluang Perkembangan Pendidikan Kejuruan Indonesia.

Muhasim. (2017). Pengaruh Tehnologi Digital, Terhadap Motivasi Belajar Peserta Didik. Palapa: Jurnal Studi Keislaman, 5(2), 53-77.

Mumtahanah, N. (2015). Pengembangan Sistem Pendidikan Pesantren dalam 
Meningkatkan Profesionalisme Santri. AL HIKMAH Jurnal Studi Keislaman, 5(1), 1-17.

Muslima (2015). POLA ASUH ORANG TUA TERHADAP KECERDASAN FINANSIAL ANAK Muslima. Gender Equlity: International Journal Of Child and Gender Studies, 1(1), 85-98.

Faisal, N. (2016). Pola Asuh Orang Tua Dalam Mendidik Anak di Era Digital. AnNisa', IX(2), 128.

Putrawangsa, S., \& Hasanah, U. (2018, August 29). INTEGRASI TEKNOLOGI DIGITAL DALAM PEMBELAJARAN DI ERA INDUSTRI 4.0. Jurnal Tatsqif, 16(1), 42-54. $\quad$ Retrieved from http://journal.uinmataram.ac.id/index.php/tatsqif/article/view/203 Adawiah, R. (2017). Pola Asuh Orang Tua dan Implikasinya terhadap Pendidikan Anak: Studi pada Masyarakat Dayak di Kecamatan Halong Kabupaten Balangan. Jurnal Pendidikan Kewarganegaraan, 7(1), 33-48.

Rozana, A. A., Wahid, A. H., \& Muali, C. (2017). Smart Parenting Demokratis Dalam Membangun Karakter Anak. Al-Athfal Jurnal Pendidikan Anak, 4(1), 1-16.

Rahmat, S. T. (2018). POLA ASUH YANG EFEKTIF UNTUK MENDIDIK ANAK DI ERA DIGITAL. Jurnal Pendidikan Dan Kebudayaan Missio, 10(2), 143-161. 